\title{
Clinicodemographic Profile and Outcome of Maintenance Hemodialysis Patients in a Tertiary Hospital of Central Nepal, Chitwan Ghimire $\mathrm{M},{ }^{1}$ Vaidya $\mathrm{S},{ }^{1}$ Upadhyay $\mathrm{HP}^{2}$
}

${ }^{1}$ Department of Nephrology

${ }^{2}$ Department of Community Medicine

College of Medical Sciences Teaching Hospital,

Bharatpur, Nepal.

\section{Corresponding Author}

Madhav Ghimire

Department of Nephrology

College of Medical Sciences Teaching Hospital,

Bharatpur, Nepal.

E-mail: madhavghimirenp@yahoo.com

\section{Citation}

Ghimire M, Vaidya S, Upadhyay HP. Clinicodemographic Profile and Outcome of Maintenance Hemodialysis (MHD) Patients in a Tertiary Hospital of Central Nepal, Chitwan. Kathmandu Univ Med J. 2020;69(1):9-14.

\section{ABSTRACT}

\section{Background}

Maintenance hemodialysis is a popular treatment modality of renal replacement therapy for end stage renal disease patients; however their mortality seemed to be rising in our centre. There were no previous studies regarding the clinicodemographic profile and outcome of maintenance hemodialysis patients from this region.

\section{Objective}

This study was carried out with an objective to know the clinicodemographic profile and outcome of maintenance hemodialysis patients in our centre.

\section{Method}

This study was a hospital based prospective observational study carried out over a period of three year, from May 2016 to April 2019, in the hemodialysis unit of the department of nephrology. All the consecutive end stage renal disease patients on maintenance hemodialysis were included in the study. The patient's demographic profile and outcome were studied and analysed using appropriate statistical tools.

\section{Result}

A total of 156 patients were enrolled in the study. Males were 96(61.5\%) and females were $60(38.5 \%)$. The mean age of the patient was $52.2 \pm 15.6$ years. The commonest causes of end stage renal disease and reasons for admission were Type 2 diabetes mellitus $68(43.6 \%)$ and volume overload with heart failure $101(64.7 \%)$ respectively. At the end of three years, 39(25\%) were expired, 14(8.9\%) were transferred to other centre and four $(2.6 \%)$ underwent kidney transplantation. The average duration of hemodialysis was $20.3 \pm 17.5$ months. Majority of the patients $154(98.7 \%)$ had repeat admission ranging from 1 time $21(13.5 \%)$ to 10 times two (1.3\%). There was a significant association between age $\geq 40$ years and diabetes with mortality ( $p$ value $<$ 0.003 and $<0.028$ respectively).

\section{Conclusion}

The commonest cause of end stage renal disease and the reason of admission were Type 2 diabetes mellitus 68 (43.6\%) and volume overload with heart failure 101 (64.7\%) respectively. The overall mortality was 39 (25\%) and the commonest cause of mortality was sepsis/health care associated pneumonia 30 (76.9\%). There was significant association between age $\geq 40$ years and diabetes with mortality ( $p$ value $<$ 0.003 and $<0.028$ respectively).

\section{KEY WORDS}

Diabetes mellitus, End stage kidney disease, Maintenance hemodialysis 


\section{INTRODUCTION}

Maintenance hemodialysis (MHD) is a popular treatment modality for end stage renal disease (ESRD) patients to prolong their life. ESRD is rising globally and the reasons that might have contributed to the rise in the prevalence of ESRD are multifactorial. ${ }^{1}$ About 50 years ago, ESRD was invariably a fatal condition but with the advent of maintenance hemodialysis, the patient survival has increased but their mortality remains high and is a matter of great concern. ${ }^{2}$

In Nepal, hemodialysis service was started in 1987 and since then ESRD patients continue to rise and die prematurely due to poor health care system, lack of dialysis service centres and its cost. ${ }^{3}$ However, lately the scenario has changed as Nepal government has started providing free hemodialysis service to the MHD patients making hemodialysis an accessible and affordable treatment option. Though the true data regarding the incidence of ESRD is lacking in our country, a retrospective multicentric study done by Hada et al. revealed the incidence of ESRD to be 3.4 per million populations (pmp) in 1990 to 11.89 pmp in 1999 with an average annual incidence of $6 \mathrm{pmp}$ and of them only $0.31 \%$ received renal replacement therapy (RRT). ${ }^{4}$

We had realized that the ESRD patients and their mortality were increasing in our centre. However there were no previous studies regarding the clinical and demographic profile and outcome of MHD patients from this region. We therefore thought of doing a study to know the clinicodemographic profile and outcome of maintenance hemodialysis patients in our centre.

\section{METHODS}

This study was a hospital based prospective observational study carried out over a period of three year, from May 2016 to April 2019, in the hemodialysis unit of the department of nephrology. All the consecutive ESRD patients on MHD irrespective of their age, sex and renal diagnosis were included in the study. The clinical diagnosis of renal diseases were made by a nephrologist with an experience of $>5$ years in clinical Nephrology and all the diagnoses were supported by relevant biochemistry, radiology and pathology reports. The standard definitions were used to define the renal diagnosis as per the updated Kidney Disease Improving Global Outcome (KDIGO) equivalent criteria, wherever applicable. Written informed consents were taken from the patients. The ethical clearance for the study was taken from the Institutional review committee of the hospital. The standard maintenance hemodialysis procedure was carried out for 4 hours once, twice, thrice or every two weekly depending on the clinical need of the patient. The Fresenius 4008S machines were used for hemodialysis with a reverse-osmosis water treatment system. The Polysulfone hollow fibre dialyzers (Fresenius F6HPS) with surface area $1.3 \mathrm{~m}^{2}$ area and ultrafiltration co- efficient $10-16 \mathrm{ml} / \mathrm{h} / \mathrm{mmHg}$ were used in all patients. The dialysate flow rate was $500 \mathrm{ml} / \mathrm{min}$ and blood flow rates were targeted as per the patient requirement and the tolerability ranging from $180-350 \mathrm{ml} / \mathrm{min}$. The dialyzer reuse was performed using automated Renatron machine.

The patient's demographic profile, clinical diagnosis, body mass index (BMI), cause of ESRD, duration of hemodialysis, number of sessions per week, vascular access, and reasons of hospitalizations, number of hospitalization and the cause of death were noted in the proforma. The data were then entered in the MS XP sheet and were transferred to SPSS version 20 (Chicago, IL, USA) programme for analysis. The data were analysed using appropriate statistical tools. The continuous variables were expressed as mean \pm standard deviation (SD) and ratio. The categorical variables were expressed as frequency, percentage and the Chisquare test. The variables like age, body mass index (BMI) and cause of ESRD were studied for their association with mortality using Chi-square test. The confidence interval was kept at $95 \%$, and a $p$ value $<0.05$ was considered statistically significant.

\section{RESULTS}

A total of 156 patients were enrolled in the study. Out of them 96 (61.5\%) were males and 60 (38.5\%) were females. The mean age of the patient was 52.2 years with a standard deviation of \pm 15.6 years. The minimum age was 17 years and maximum age was 80 years.

Table 1. Age distribution of patients $(n=156)$

\begin{tabular}{|lllll|}
\hline Age (in years) & Number & $\begin{array}{l}\text { Total (Male }+ \text { Percentage } \\
\text { Female) }\end{array}$ \\
\hline $1-20$ & Male & Female & & \\
\hline $21-40$ & 3 & 2 & 5 & 3.2 \\
\hline $41-60$ & 17 & 12 & 29 & 18.6 \\
\hline $61-80$ & 39 & 31 & 70 & 44.9 \\
\hline$>80$ & 37 & 15 & 52 & 33.3 \\
\hline
\end{tabular}

In terms of age distribution, 34 (21.8\%) were of age $<40$ years and $122(78.2 \%)$ were of age $\geq 40$ years. The patients who were of $\leq 20$ years were five (3.2\%), 21-40 were 29 (18.6\%), 41- 60 were 70 (44.9\%), 61-80 were 52 (33.3\%) and $>80$ years were none.

The vascular accesses used for hemodialysis were arteriovenous (AV) fistula 135 (86.5\%), temporary internal jugular catheter 16 (10.3\%), femoral catheter three (1.9\%) and permanent catheter two (1.3\%). The patients who were on 2 session of hemodialysis (HD) per week were 130 (83.3\%), 1 session per week were $23(14.7 \%)$ and 3 session per week were three (1.9\%).

A total of 39 (25\%) patients died during the study period. The mean age of the patient who died was $61.2 \pm 10.4$ 
Table 2. Causes of ESRD of MHD patients $(n=156)$

\begin{tabular}{|lll|}
\hline Causes of ESRD & Number of patients & Percentage \\
\hline Type 2 Diabetes mellitus (T2DM) & 68 & 43.6 \\
\hline Chronic Glomerulonephritis (CGN) & 42 & 26.9 \\
\hline Hypertension (HTN) & 41 & 26.3 \\
\hline $\begin{array}{l}\text { Autosomal dominant polycystic } \\
\text { kidney disease }\end{array}$ & 1 & 0.6 \\
\hline $\begin{array}{l}\text { Obstructive Uropathy } \\
\text { Neurogenic bladder }\end{array}$ & 1 & 0.6 \\
\hline $\begin{array}{l}\text { Congenital anomalies of kidney } \\
\text { urinary tract }\end{array}$ & 1 & 0.6 \\
\hline Renal Calculus Disease (RCD) & 1 & 0.6 \\
\hline
\end{tabular}

Table 3. Reasons of hospital admissions of MHD patients ( $n=156)$

\begin{tabular}{lll}
\hline Reasons of admissions & Number of patients & Percentage \\
$\begin{array}{l}\text { Volume overload with heart } \\
\text { failure }\end{array}$ & 101 & 64.7 \\
\hline $\begin{array}{l}\text { Sepsis/ Health care associated } \\
\text { pneumonia }\end{array}$ & 43 & 27.6 \\
\hline $\begin{array}{l}\text { Catheter related blood stream } \\
\text { infection }\end{array}$ & 6 & 3.8 \\
\hline $\begin{array}{l}\text { Sepsis/Complicated urinary tract } \\
\text { infection }\end{array}$ & 3 & 1.9 \\
\hline $\begin{array}{l}\text { Arteriovenous fistula site infec- } \\
\text { tion }\end{array}$ & 1 & 0.6 \\
\hline $\begin{array}{l}\text { Uremic encephalopathy } \\
\text { Uremic seizure }\end{array}$ & 1 & 0.6 \\
\hline
\end{tabular}

Table 4. Outcome of MHD patients over three years $(n=156)$

\begin{tabular}{|lll|}
\hline Outcome & Number of patients & Percentage \\
\hline Alive and on regular MHD & 98 & 62.8 \\
\hline Expired & 39 & 25 \\
\hline Transferred to other HD centre & 14 & 8.9 \\
\hline Left without notice & 1 & 0.6 \\
\hline $\begin{array}{l}\text { Undergone kidney transplanta- } \\
\text { tion }\end{array}$ & 4 & 2.6 \\
\hline
\end{tabular}

years. The causes of death were sepsis/health care associate pneumonia (sep/HCAP) $30(76.9 \%)$, heart failure eight (20.6\%) and myocardial infarction one (2.5\%). The average duration of hemodialysis was $20.3 \pm 17.5$ months. The patient with the shortest duration in dialysis was 1 month and the longest duration was 72 months and still surviving. The patients with $<1$ year duration of dialysis were $63(40.4 \%), 1-5$ years duration of dialysis were 84 $(53.8 \%)$ and $>5$ years duration of dialysis were nine $(5.8 \%)$. Only one $(0.6 \%)$ patient seroconverted to $\mathrm{HbsAg}$ positive status. None of the patient seroconverted to hepatitis $C$ virus (HCV) and human immunodeficiency virus (HIV). Body mass index (BMI) less than $18.5 \mathrm{Kg} / \mathrm{m}^{2}$ were seen in $26(16.7 \%)$ patients, between $18.5-24.9 \mathrm{Kg} / \mathrm{m}^{2}$ were seen in $82(52.6 \%)$, and $\geq 25 \mathrm{Kg} / \mathrm{m}^{2}$ were seen in $48(30.8 \%)$ patients. Only two (1.3\%) patients didn't had any hospital admissions rest all had admission from 1 time 21 (13.5\%) to 10 times $2(1.3 \%)$.

Table 5. Episodes of repeat admissions of MHD patients over three years $(n=156)$

\begin{tabular}{|lll|}
\hline Episodes of repeat admissions & Number of patients & Percentage \\
\hline One time repeat admission & 21 & 13.5 \\
\hline Two times repeat admissions & 32 & 20.5 \\
\hline Three times repeat admissions & 28 & 17.9 \\
\hline Four times repeat admissions & 31 & 19.8 \\
\hline Five times repeat admissions & 16 & 10.2 \\
\hline Six times repeat admissions & 12 & 7.7 \\
\hline Seven times repeat admissions & 5 & 3.2 \\
\hline Eight times repeat admissions & 5 & 3.2 \\
\hline Nine times repeat admissions & 2 & 1.3 \\
\hline Ten times repeat admissions & 2 & 1.3 \\
\hline
\end{tabular}

Table 6. Associations between age, diabetes and low BMI and the mortality

\begin{tabular}{|llll|}
\hline Variables & No Mortality & Mortality & P value \\
\hline Age $<40$ years & 32 & 2 & \\
\hline Age $\geq 40$ years & 85 & 37 & $<0.003$ \\
\hline Diabetic Kidney Disease & 45 & 23 & $<0.028$ \\
\hline Non Diabetic Kidney Disease & 72 & 16 & \\
\hline BMI $<18.5 \mathrm{Kg} / \mathrm{m}^{2}$ & 13 & 13 & $>0.05$ \\
\hline BMI $18.5-24.9 \mathrm{Kg} / \mathrm{m}$ & 60 & 22 & \\
\hline BMI $18.5-24.9 \mathrm{Kg} / \mathrm{m}$ & 44 & 4 & \\
\hline
\end{tabular}

\section{DISCUSSION}

To the best of our knowledge, this study was the first of its kind from Chitwan. Males 96 (61.5\%) were more in number than females 60 (38.5\%), which was similar to some studies done in India. 5,6 Similarly males outnumbered the females with $\mathrm{M}: \mathrm{F}$ ratio of $\sim$ 2:1 in dialysis outcome practice pattern study (DOPPS) and other Indian studies. ${ }^{7,8-11}$ This dominance of males over the female may reflect the socio-dynamic influence of our society, where a treatment privilege goes to males or it could be because of the fact that the males are inherently at increased risk to develop kidney diseases. This area of research needs multicentric genetic studies.

The mean age of patients in our study was $52.2 \pm 15.6$ years which was not much different from that reported by AlWakeel et al. (53.7 years). ${ }^{12}$ Similar mean age was seen in Okinawa Dialysis Study (OKIDS) Registry (55.9 years), however it was lower than that seen in united states renal data system (USRDS) 2008 data (64.4 years). ${ }^{13,14}$ The mean age of starting the dialysis was in the fifties. This was sad to see people starting the MHD in their fifties, when normally they were supposed to be productive and active. 
The commonest cause of ESRD in our study was T2 DM 68 (43.6\%) followed by CGN 42 (26.9\%) and HTN 41 (26.3\%). The etiologic patterns for ESRD observed in our study were consistent with some Indian studies and chronic kidney disease (CKD) registry of India. ${ }^{8,10,11}$ However in contrary, Sathyan et al. found CGN (51.0\%) and diabetic nephropathy $(22.0 \%)$ to be the most common aetiologies. ${ }^{15}$ In another study, Chaudhari et al. found diabetic nephropathy (32.0\%), hypertensive nephropathy $(20.0 \%)$ and chronic glomerulonephritis (10.0\%) to be the most common etiology of CKD and Jha et al. in their study found diabetic nephropathy (31.2\%) and hypertensive nephropathy $(12.8 \%)$ to be the most common aetiologies of CKD. ${ }^{16,17}$ This highlights that there is considerable variation in the causes of ESRD within and across the country.

The commonest reason for hospital admission was volume overload with heart failure 101(64.7\%) followed by sepsis/ HCAP (27.6\%), which was similar to studies done in Saudi arebia. ${ }^{12,18}$ The volume overload with heart failure as the commonest reason of hospital admission can be explained by the poor fluid and salt compliance of the patients. Sepsis/HCAP was the second important cause of admission. This again highlights the increasing burden of sepsis in our region. Kidney disease patients especially ESRD are 100300 times increased risk of infection. ${ }^{19}$

The majority of the patients in our study initiated the hemodialysis through a femoral catheter 110 (70.5\%) and an uncuffed dual lumen hemodialysis (HD) catheter $40(25.6 \%)$, this finding was different from that seen in some Indian studies, where the internal jugular catheter was the most common form of vascular access used for hemodialysis initiation. ${ }^{10,20}$ Only few patients six (3.8\%) in our study had mature arteriovenous (AV) fistula at the time of presentation, which was similar to the observations made in other studies from India. ${ }^{10,11,20}$ This low AV fistula rate six (3.8\%) might be due to late referral of CKD patients for AV fistula creation and treatment of CKD done by general physician with conservative approach until late. ${ }^{11,21}$ However we had seen a good conversion to AV fistula 135 (86.5\%) during the course of the treatment in dialysis unit, which was similar to a study from India by Chandrashekar et al. ${ }^{8}$

Lately, Nepal government had started free HD service for MHD patients and to make this a sustainable and cost effective programme two times per week schedule was implemented as the standard of care. However, international guidelines recommend using incremental hemodialysis using the residual renal function to decide the dose and frequency of dialysis. ${ }^{22}$ We don't have any studies from Nepal establishing the inferiority of two times versus three times per week dialysis dose. Hence, majority of the patients 130 (83.3\%), in our study were on two times per week schedule which was the standard HD prescription pattern in most of the other centres of Nepal. We need to conduct a large multicentric study to understand the superiority or inferiority of two times versus three times per week dialysis session to better quantify the dosing of dialysis in our population.

Over a period of 3 years, 39 (25\%) patients expired. which was considerably higher than that reported by Rao et al. (9.5\%) and Mittal et al. (12.5\%) but was comparable with the United States renal data system (USRDS) data (21\%). ${ }^{9,23,24}$ In one study the adjusted rates of all-cause mortality are 6.3-8.2 times greater for dialysis patients than the general population. ${ }^{25}$ The average age of patients who expired in our study were in middle age (60.1 \pm 10.4$)$, which was higher than that of overall cohort $(52.2 \pm 15.6)$ suggesting the death was more in higher age group and there was a significant association between age $\geq 40$ years and the mortality ( $p$ value $<0.003$ ) signifying that the older age was a risk factor for mortality. There was also a significant association between diabetes and the mortality ( $p$ value $<0.028$ ) suggesting diabetes is a risk factor for mortality. Similar association of diabetes and mortality were seen in studies from Saudi Arabia and India. ${ }^{12,17}$ But there was no significant association between sex and the mortality ( $p$ value $>0.05$ ). However a study by Depner et al. demonstrated a survival advantage in females. ${ }^{26}$

Sepsis 30 (76.9\%) was the commonest cause of mortality in our study and health care associate pneumonia (HCAP) was the commonest cause of sepsis, whereas vascular access-related infections (abscess of the AVF and catheterrelated bacteraemia) were the most common cause of sepsis in other study from India. ${ }^{20}$ Inadequate hemodialysis and withdrawal from dialysis were also reported as the causes of death in that study. ${ }^{20}$ However in contrast to our study, a study from Unites States of America (USA) showed cardiovascular events to be the most common cause of mortality followed by infectious. ${ }^{24}$ Signifying that the cause of death differs in developing and developed world.

Of the 156 patients, only four (2.6\%) of the patients had undergone kidney transplantation in our study, which was a low conversion rate considering the burden of ESRD patients in our centre. However, this low conversion rate might not reflect the true conversion figure because many of the patients had lost to follow up and did not report back. Similarly, in a study done by Hada et al. from Nepal, there was a low conversion rate of kidney transplantation, of 1393 patients, $9.5 \%$ had undergone kidney transplantation. ${ }^{4}$ This low conversion of transplantation might be because of donor issue, age factor, medical reasons, and financial issues, lack of family support or combination of one or the other.

Majority of the patient in our study had normal to overweight $\mathrm{BMI}$, making under nutrition a less prevalent problem 26(16.7\%) and there was no significant association between low BMI and mortality ( $p$ value $\geq$ $0.5 \%)$, which was in contrast to studies done by Owen et al. and Dwyer et al. who had demonstrated an increased mortality in undernourished. ${ }^{27,28}$ This might be because of 
the fact that our patient were above their dry weight to begin with because of poor fluid compliance and volume overload, which might have falsely under estimated the true malnutrition prevalence. Malnutrition per se is an important determinant of adverse outcome like increased number of hospitalizations and mortality in dialysis.

Majority of the patient 154 (98.7\%) in our study had admissions from 1 time to 10 times. Only two (1.3\%) patients in the study didn't have any admission. In a study done by Kshirsagar et al. the majority (73.0\%) had single admissions, $21 \%$ had two admissions, and approximately only $2 \%$ (three patients) had four hospitalizations. ${ }^{29}$ The maximum number of readmissions up to 10 times two $(1.3 \%)$ in our study might highlight a high infection burden and the poor fluid and salt compliance of the patients. Sepsis and volume overload were two important causes of admissions. In our study, the seroconversion rate of $\mathrm{HbsAg}$ was one $(0.6 \%)$. However, none of the patient had seroconverted to HCV or HIV status. This low seroconversion might be due to better quality check and screening of viral markers before blood transfusion or the method of testing used. We had used antibody testing rather than nucleic acid testing that might have under represented the true incidence of seroconversion.

There were few limitations in this study. Foremost being an observational study; all the inherent limitations of an observational study were there in the study. This was also a single centre study, so the results might not be

\section{REFERENCES}

1. United States Renal Data System, USRDS 2010 Annual Data Report: Atlas of Chronic Kidney Disease and End-Stage Renal Disease in the United States, National Institutes of Health, National Institute of Diabetes and Digestive and Kidney Diseases, Bethesda, MD, 2010.

2. Pozzoni P, Del Vecchio L, Pontoriero G, Di Filippo S, Locatelli F. Long-term outcome in hemodialysis: Morbidity and mortality. J Nephrol. 2004; 17 Suppl 8: S87-95.

3. Chhetri PK, Satyal PR, Kafle R, Khakurel S, Pradhan BR. Experience of hemodialysis in Bir Hospital. Nepal Med Coll J. 1999; 1: 99-101.

4. Hada R, Khakurel S, Agrawal RK, Kafle RK, Bajracharya SB, Raut KB. Incidence of end stage renal disease on renal replacement therapy in Nepal. Kathmandu University Medical Journal. 2009; 27: 301-5.

5. Dharan KS, John GT, Neelakantan N. Spectrum of severe chronic kidney disease in India: A Clinicopathological study. Natl Med J India 2006; 19: 250-2.

6. Modi GK, Jha V. The incidence of end-stage renal disease in India: A population based study. Kidney Int. 2006; 70(12): 2131-3.

7. Hecking M, Bieber BA, Ethier J, Kautzky-Willer A, Sunder-Plassmann $G$, Säemann $M D$, et al. Sex-specific differences in hemodialysis prevalence and practices and the male-to-female mortality rate: The dialysis outcomes and practice patterns study(DOPPS). PLOS Med. 2014;11:e1001750.

8. Chandrashekar A, Ramakrishnan S, Rangarajan D. Survival analysis of patients on maintenance hemodialysis. Indian J Nephrol. 2014; 24: 206-13.

9. Rao M, Juneja R, Shirly RB, Jacob CK. Hemodialysis for end-stage renal disease in Southern India- A perspective from a tertiary referral care center. Nephrol Dial Transplant. 1998; 13: 2494-500. generalizable to whole region and the country, highlighting the need for multicentric studies. Our study did not study the impact of HBV or HCV status on mortality. Similarly, the erythropoietin resistance and its impact on mortality were not assessed. Most importantly, dialysis adequacy or residual renal functions were not calculated and their impacts on mortality were not assessed.

\section{CONCLUSION}

There was dominance of males 96 (61.5\%) in the study. The average age of the patient was $52.2 \pm 15.6$ years. The commonest cause of ESRD and the reasons of admission were T2 DM 68 (43.6\%) and volume overload with heart failure 101 (64.7\%) respectively. The overall mortality was $39(25 \%)$ and the commonest cause of mortality was sepsis/HCAP 30 (76.9\%). There was significant association between age $\geq 40$ years and mortality ( $p$ value $<0.003$ ) and similarly significant association between diabetes and mortality ( $p$ value $<0.028$ )

\section{ACKNOWLEDGEMENT}

We would like to thank all the patients, hemodialysis nursing staffs, hemodialysis technician, hemodialysis coordinator, PG residents and Interns of department of nephrology, who had directly and indirectly helped in the study.

10. Swarnalatha G, Ram R, Prasad N, Dakshinamurty KV. End-stage renal disease patients on hemodialysis: A study from a tertiary care center in a developing country. Hemodial Int. 2011; 15: 312-9.

11. Rajapurkar MM, John GT, Kirpalani AL, Abraham G, Agarwal SK, Almeida AF et al. What do we know about chronic kidney disease in India: First report of the Indian CKD registry? BMC Nephrol. 2012; 13: 10.

12. Al-Wakeel JS, Mitwalli AH, Al Mohaya S, Abu-Aisha H, Tarif N, Malik $\mathrm{GH}$ et al. Morbidity and mortality in ESRD patients on dialysis. Saudi J Kidney Dis Transplant. 2002; 13(4): 473-7.

13. Iseki K, Tozawa M, Iseki C, Takishita S, Ogawa Y et al. Demographic trends in the Okinawa Dialysis Study (OKIDS) registry (1971- 2000). Kidney Int. 2002; 61: 668-675.

14. US Renal Data System. USRDS 2008 Annual Data Report: Atlas of Chronic Kidney Disease and End-Stage Renal Disease in the United States, Bethesda, MD: National Institutes of Health, National Institute of Diabetes and Digestive and Kidney Diseases, 2008.

15. Sathyan S, George S, Vijayan P, Jayakumar M. Clinical and epidemiological profile of chronic kidney disease patients in a tertiary care referral centre in South India. International Journal of Community Medicine and Public Health. 2016 Dec 22; 3(12): 3487-92.

16. Chaudhari ST, Sadavarte AV, Chafekar D. Clinical Profile of End Stage Renal Disease in Patients Undergoing Hemodialysis. MVP Journal of Medical Science. 2017 May 22; 4(1): 8-13.

17. Jha V. Current status of end-stage renal disease care in India and Pakistan. Kidney Int Suppl. 2013; 3(2): 157-60. 
18. Al Muhanna FA, Saeed I, Al Muelo S, Larbi E, Rubaish A. Disease profile, complications and outcome on maintenance hemodialysis at King Faisal University Hospital, Saudi Arabia. East Afr Med J. 1999; 76(12): 664-7.

19. Sarnak MJ, Jaber BL. Mortality caused by sepsis in patients with endstage renal disease compared with the general population. Kidney Int. 2000; 58: 1758-1764.

20. Bhowmik D, Tiwari SC. Challenges of hemodialysis in India. JIMSA. 2012; 25: 99-100.

21. Astor BC, Eustace JA, Powe NR, Klag MJ, Sadler JH, Fink NE et al. Timing of nephrologist referral and arteriovenous access use: The CHOICE study. Am J Kidney Dis. 2001; 38: 494-501.

22. ISN Hemodialysis Guideline Workgroup. Indian Society of Nephrology guidelines on hemodialysis units. Indian J Nephrology. 2012; 22 Suppl: 28.

23. Mittal S, Kher V, Gulati S, Agarwal LK, Arora P. Chronic renal failure in India. Ren Fail. 1997; 19: 763-70.
24. United States Renal Data System. Excerpts from USRDS 2008 Annual Data Report. U.S. Department of Health and Human Services. The National Institutes of Health, National Institute of Diabetes and Digestive and Kidney Diseases. Am J Kidney Dis. 2009; 1 Suppl 1: S1.

25. Collins AJ, Foley RN, Herzog C, Chavers B, Gilbertson D, Herzog C, et al. US Renal Data System 2012 Annual Data Report. Am J Kidney Dis. 2013; 61: A7, e1-476.

26. Depner T, Daugirdas J, Greene T, Allon M, Beck G, Chumlea C, et al. Dialysis dose and the effect of gender and body size on outcome in the HEMO Study. Kidney Int. 2004; 65: 1386-94.

27. Owen WF Jr, Lew NL, Liu Y, Lowrie EG, Lazarus JM. The urea reduction ratio and serum albumin concentration as predictors of mortality in patients undergoing hemodialysis. N Engl J Med. 1993; 329: 1001-6.

28. Dwyer JT, Larive B, Leung J, Rocco MV, Greene T, Burrowes J, et al. Are nutritional status indicators associated with mortality in the Hemodialysis (HEMO) Study? Kidney Int. 2005; 68: 1766-76.

29. Kshirsagar AV, Hogan SL, Mandelkehr L, Falk RJ. Length of Stay and Costs for Hospitalized Hemodialysis Patients: Nephrologists versus Internists. J Am Soc Nephrol. 11: 1526-33. 